\title{
Decolonization and Reconciliation work in Public Libraries: An Analysis of Strategic Plans (Paper)
}

\begin{abstract}
The 2015 Truth and Reconciliation Commission of Canada report provides valuable guidance and critical foundation on decolonization and reconciliation in Canada. Public institutions including universities and libraries have affirmed their commitment towards reconciliation and decolonization by undertaking initiatives and establishing both short- and long-term goals. This research examines strategic plans posted on the organizational websites of nine Canadian public library systems operating in cities with significant Indigenous population. The findings suggest that different library systems made varying levels of explicit and/or implicit commitment towards reconciliation and decolonization.
\end{abstract}

\section{Introduction}

Decolonization involves removing both visible and invisible barriers and structures which bring colonial power and control into play (Ashcroft et al. 2001; Smith 2010). The 2015 Truth and Reconciliation Commission of Canada (TRC 2015) report provides guidance and recommendations (e.g., 94 Calls to Action) to institutions (e.g., museum, archives and libraries) on reconciliation with Indigenous Peoples of Canada. Reconciliation is "an ongoing process" (TRC 2015 p.16) that involves creating "a mutually respectful relationship between Aboriginal and non-Aboriginal peoples" (ibid p.6) and "following through with concrete actions that demonstrate real societal change" (ibid p.16). Public libraries, for example, demonstrate their commitment towards reconciliation and decolonization by taking actions in a number of areas such as spaces (online and physical), programs and services, and collections (Rathi and Wiebe 2020). Organizations (e.g., public libraries) and leaders institutionalize (Cox et al. 1997) their commitments and actions by incorporating specific goals and objectives in strategic plans to demonstrate their resolve to stakeholders (Moropa 2010; Millesen et al. 2010). Thus, public institutions including public libraries can demonstrate their commitment towards decolonization and reconciliation by setting goals and objectives in their strategic plans. This paper presents findings emerging from the analysis of the strategic plans posted on the organizational websites of nine Canadian public libraries. The paper aims to fill a gap in literature in the critical area of decolonization and reconciliation in the Library and Information Science (LIS) field in the Canadian context, particularly public libraries. The aim of this research is also to prompt LIS institutions to include decolonization- and reconciliation-oriented efforts as goals and objectives in their future iterations of strategic plans.

\section{Literature Review}

The Truth and Reconciliation Commission of Canada (TRC) provides valuable foundation, and critical guidance on decolonization and reconciliation to Canadian institutions (TRC 2015). The literature in this area is limited but evolving with time. McGibbon (2019) reflected on TRC in 
context of healthcare and noted that leadership "have a key role in enacting" TRC's Calls to Action (p.20) while Maestro and Chadwick (2017) examined the response of health libraries to TRC. Authors such as McGowan et al. (2020), Gaudry and Lorenz (2018), and Bissell and Korteweg (2016) examined the education landscape, and Wiebe and Rathi (2020) examined library-related associations' efforts towards decolonization and reconciliation. There is ongoing research to identify ways to decolonize various areas in the LIS field such as record description (e.g., Fangan 2020; Farnel et al. 2018; Vaughan 2018), library services (e.g., Edwards 2019), attributions (e.g., Anderson and Christen 2019), and other areas such as library spaces, program and collection (Rathi and Wiebe 2020). There are limited studies (e.g., Tembo 2018) that have examined strategic plans from a reconciliation perspective. Tembo (2018), for example, analyzed "the long-range strategic plans of Canada's 22 Big Cities" and their alignment with "the TRC's Principles of Reconciliation" (p.6).

\section{Methodology}

The strategic plans of nine Canadian public libraries were analyzed to learn about decolonization and reconciliation efforts. The top ten Canadian cities having the largest Indigenous population as per the 2016 Census data of Statistics Canada (Statistics Canada, 2016; Anderson, 2019) were identified to shortlist public library systems, and they are: Winnipeg Public Library (WPL), Edmonton Public Library (EPL), Vancouver Public Library (VPL), Toronto Public Library (TPL), Calgary Public Library (CPL), Ottawa Public Library (OPL), Bibliothèques Montréal (BM), Saskatoon Public Library (SPL), Regina Public Library (RPL), and Greater Victoria Public Library (GVPL). BM was not included in this analysis due to researcher's French language limitations.

The strategic plans from the nine public libraries as posted on their websites were downloaded, browsed and searched for Indigenous-related content. A single coder collated and analyzed the data using the thematic analysis approach (Clarke and Braun 2017; Vaismoradi et al. 2013). The CFLA-FCAB Report (2017) provides a number of recommendations (e.g., see p.6-7), which were foundational in undertaking the analysis. The strategic plans were searched using key words such as Indigenous, Aboriginal, First Nation, Métis, TRC, Treaty, Land Acknowledgement, and Calls

to Action. This research has limitations including coding by a single reviewer, and reviewing strategic planning documents, as posted on the organizational websites, which could be a summarized version of the actual document. Also, there might be other relevant (multiple) planning documents that were not posted on the websites and/or did not show up in the search results.

\section{Key Findings}

The start year of the strategic plans of eight (out of nine) public libraries was after the publication date of the TRC's report (2015) with the exception being WPL's strategic plan (2015-2020), which had the same start year (i.e., 2015). There were varying levels of details in the strategic plan documents posted by libraries on their websites. For example, the strategic direction and priorities posted on a single webpage by OPL to a 52-page (PDF) document posted by TPL. The analysis revealed both explicit and implicit commitments of public libraries towards decolonization and reconciliation. 


\subsection{Explicit Commitment}

A majority of public libraries expressed their explicit commitment towards reconciliation and decolonization by responding and committing through specific actions as evident from review and analysis of the strategic plans.

\subsubsection{Including Treaty, and Land Acknowledgement}

This facet connects to the CFLA-FCAB's (2017) recommendation\#6: “...territorial acknowledgements..." (p.6). Strategic plans were browsed and/or searched using keywords such as land acknowledgement and treaty including abbreviated terms (e.g., 'acknow'). The majority of the public library systems did not include land acknowledgements except for TPL, which had the land acknowledgement in their strategic plan (see p.7, TPL n.d.). Other libraries like CPL connected to reconciliation by reflecting on the specific treaty in their document. It noted that it will be "forging a path of Reconciliation by listening to... particularly those of the Treaty 7 region..." (CPL n.d. p.4)

\subsubsection{Responding to TRC and Calls to Action}

This facet connects to the CFLA-FCAB's (2017) recommendation\#3: "Encourage libraries ... to implement... 94 Calls to Action" (p.6). Four libraries (TPL, EPL, VPL and SPL) explicitly mentioned Calls to Action in their documents. For example: VPL (2016), EPL (n.d.) and SPL (n.d.) noted "commitment to addressing... Calls to Action within VPL..." (p.26), "implement... Calls to Action through public classes and events, and staff training" (p.24), and "[r]espond in meaningful ways to... Calls to Action..." (p.18), respectively.

\subsubsection{Supporting Indigenous Cultures}

This facet connects to the CFLA-FCAB's (2017) recommendation\#6: “...recognizing and supporting Indigenous cultures..." (p.6). Some public libraries included programs and services goals/objectives with focus on Indigenous communities. A select few libraries such as CPL and SPL explicitly discussed ways they are going to recognize and support Indigenous cultures. For example: CPL's strategic initiative includes expansion of "Indigenous Placemaking" (n.d. p.5), and; SPL (n.d.) is committed to "elevate Indigenous voices by promoting languages, cultures and history" (p.16).

\subsubsection{Involving Indigenous Communities}

This facet connects to the CFLA-FCAB's (2017) recommendations\#6 and \#7: “... collaboration with local Indigenous stakeholders and partners" in various organizational matters (p.6). Libraries like TPL, CPL, EPL, VPL and SPL explicitly expressed commitment to collaborate with Indigenous communities in various organizational activities in their strategic plans. For example: TPL, EPL and CPL noted that “...established a permanent Indigenous Advisory Council ... to guide our steps ..." (n.d. p.6), "[c]ontinue our commitment to working with Indigenous communities (n.d. p. 24), and "the Library seeks to be a successful collaborator ... in the spirit of Reconciliation" (n.d. p.4), respectively. 


\subsubsection{Offering Services and Programs}

This facet connects to the CFLA-FCAB's (2017) recommendations\#6 reflecting on various facets such as "public programming" (p.6). The plan of TPL, EPL, CPL, SPL, VPL, and WPL reflected on offering services for Indigenous Peoples. For examples: WPL and SPL were committed to "[d]evelop stronger relationships with...Indigenous peoples by providing responsive programs and services" (n.d. p.7), and "[e]xplore opportunities to create an Elder-in-Residence program" (n.d. p.18), respectively.

\subsection{Implicit Commitment}

Three libraries, GVPL, RPL and OPL, had implied commitment towards decolonization and reconciliation. These libraries did not explicitly include key terms such as Indigenous, Aboriginal, and First Nation, for example, in the context of delivering programs and services or collaborating with specific communities, in their strategic plan. Libraries use 'community' (or 'communities') in various documents including strategic plans. It primarily means a group of individuals served by libraries in a particularly geographical area (Koh et al. 2018). Organizations including public libraries, normally, use 'community' (or communities) as a broad-level term to encapsulate a large number of culturally diverse communities including Indigenous communities, present in their sphere of influence (or geographical area of operations). This was evident in these libraries' plans. For examples: GVPL's goal was to "[develop] local, community-inspired [emphasis added] branch plans to increase the accessibility and impact of library services..." (2020 n.p.); OPL aimed to improve its "community relevance" [emphasis added] (n.d. n.p.), and; for RPL, "[c]ommunity is at the root of all we do..." (RPL n.d. p.6).

Strategic planning is an important activity in the management and governance of organizations. Organizations including libraries undertake strategic planning to establish priorities, and set goals and objectives (Ebertz and Stutzman 2020). It provides long-term clarity and direction, helps the organization to realize its mission and vision (Barbano 2006; Piorun 2011; Robbins and Coulter 1999), and confirms the organization's promise to its stakeholder. Organization's strategic plans are an important source of information to learn about their long-term focus and future plans on "building alignment and commitment" (Allison and Kaye 2015 p.1), and to gain insight into their specific actions (e.g., resource allocation) (ibid) and efforts they aim to undertake in various areas including decolonization and reconciliation.

\section{Conclusion}

The paper presents some of the key findings on decolonization and reconciliation efforts emerging from the analysis of the strategic plans of the nine Canadian public libraries providing services in cities with sizable Indigenous populations. The analysis revealed the explicit and implicit commitments of public libraries towards decolonization and reconciliation. There are opportunities for libraries to demonstrate not only explicit but also additional commitments in their future strategic plan iterations. The paper aims to enrich and contribute to literature, particularly in the LIS field, and to encourage public institutions to demonstrate their explicit commitment to decolonization and reconciliation by incorporating specifics in their strategic plans. This paper connects with the 'decolonizing' facet noted in the conference topics. 


\section{Reference List:}

Allison, M. and Kaye, J. (2015). Strategic Planning for Nonprofit Organizations: A Practical Guide for Dynamic Times (Third Edition), Hoboken, New Jersey: John Wiley \& Sons.

Anderson, J. and Christen, K. (2019). Decolonizing Attribution. Journal of Radical Librarianship, 5, 113-52.

Anderson, T. (2019) Insights on Canadian Society: Results from the 2016 Census: Housing, income and residential dissimilarity among Indigenous people in Canadian cities. Retrieved from https://www150.statcan.gc.ca/n1/pub/75-006-x/2019001/article/00018-eng.htm.

Ashcroft, B., Griffiths, G. and Tiffin, H. (2001). Key concepts in post-colonial studies. London, UK: Routledge.

Barbano, D. (2006). ADSA Presidential Report. Journal of Dairy Science, 89(12), 4952-4953.

Bissell, A. and Korteweg, L. (2016). Digital Narratives as a Means of Shifting Settler-Teacher Horizons toward Reconciliation. Canadian Journal of Education, 39(3),1-25.

CFLA-FCAB. (2017). Truth and reconciliation committee report and recommendations. Retrieved from http://cfla-fcab.ca/en/indigenous/trc report/.

Clarke, V. and Braun, V. (2017) Thematic analysis, The Journal of Positive Psychology, 12(3), 297-298. https://doi.org/10.1080/17439760.2016.1262613

Cox, C. C., Misra, R. and Aguillion, S. (1997). Superintendents' perceptions of schoolsite health promotion in Missouri. Journal of school health, 67(2), 50-55.

CPL. (n.d.). Calgary Public Library: Strategic Plan 2019-2022. Retrieved from https://calgarylibrary.ca/assets/PDFs/2020/2019-2022-strategic-plan-2020-initatives.pdf.

Ebertz, S. and Stutzman, K. (2020). Planning Strategically for Small Libraries. Atla Summary of Proceedings, 124-132.

Edwards, A. (2019). Unsettling the future by uncovering the past: Decolonizing academic libraries and librarianship. Partnership: The Canadian Journal of Library and Information Practice and Research, 14(1), 1-12. https://doi.org/10.21083/partnership.v14i1.5161

EPL. (n.d.). Edmonton Public Library: Strategic Goals 2019-2023, Business Plan 2019-221. Retrieved from https://d4804za1f1gw.cloudfront.net/wpcontent/uploads/sites/18/2015/06/01150026/EPLBusinessPlan2018_Booklet_FINAL_lowres _AUG2018_v5.pdf.

Fagnan, L. (2020).Decolonizing Description: First steps to cataloguing with Indigenous syllabics. Pathfinder: A Canadian Journal for Information Science Students and Early Career Professionals [Special Issue], 1(1), 33-40. https://doi.org/10.29173/pathfinder21.

Farnel, S., Koufogiannakis, D., Bigelow, I., Carr-Wiggin, A., Feisst, D., Lar-Son, K. and Laroque, S. (2018). Unsettling our practices: Decolonizing description at the University of Alberta Libraries. The International Journal of Information, Diversity, \& Inclusion (IJIDI), 2(1/2), 98-101.

Gaudry, A. and Lorenz, D. (2018). Indigenization as inclusion, reconciliation, and decolonization: Navigating the different visions for indigenizing the Canadian Academy. AlterNative: An International Journal of Indigenous Peoples, 14(3), 218-227. 
GVPL. (2020). Greater Victoria Public Library: Strategic Plan, 2016 - 2020. Retrieved from https://www.gvpl.ca/strategic-plan/.

Koh, K., Abbas, J., and Willett, R. (2018). Makerspaces in Libraries: Social Roles and Community Engagement. In Lee, V. R. and Phillips, A. L. (Eds.), Reconceptualizing Libraries: Perspectives from the Information and Learning Sciences. Routledge. https://doi.org/10.4324/9781315143422-3

Maestro, L. and Chadwick, D. (2017). Canadian health libraries' responses to the Truth and Reconciliation Commission's Calls to Action: A literature review and content analysis. Journal of the Canadian Health Libraries Association (JCHLA), 38(3), 92-101.

McGibbon, E. (2019. Truth and reconciliation: healthcare organizational leadership. In Healthcare management forum, 32(1), 20-24. Los Angeles, CA: SAGE Publications. https://doi.org/10.1177/0840470418803379.

McGowan, K., Kennedy, A., El-Hussein, M. and Bear Chief, R. (2020), "Decolonization, social innovation and rigidity in higher education", Social Enterprise Journal, 16(3), 299-316. https://doi.org/10.1108/SEJ-10-2019-0074.

Millesen, J. L., Carman, J. G. and Bies, A. L. (2010). Why engage? Understanding the incentive to build nonprofit capacity. Nonprofit Management and Leadership, 21(1), 5-20.

Moropa, R. (2010), Academic libraries in transition: some leadership issues - a viewpoint, Library Management, 31(6), 381-390. https://doi.org/10.1108/01435121011066144.

OPL. (n.d.). Ottawa Public Library: Strategic Directions and Priorities 2020-2023. Retrieved from https://biblioottawalibrary.ca/en/strategic-directions-and-priorities-2020-2023.

Piorun, M. (2011). Evaluation of strategic plans in academic medical libraries. Library \& Information Science Research, 33(1), 54-62.

Rathi, D. and Wiebe, R. (2020). Decolonization Efforts by Canadian Public Libraries. Proceeding of the $48^{\text {th }}$ Annual Conference of the Canadian Association for Information Science / l'Association canadienne des sciences de l'information (CAIS/ACSI), 1-6. https://doi.org/10.29173/cais1133.

Robbins, S. P. and Coulter, M. (1999). Management (6 ${ }^{\text {th }}$ Edition), Upper Saddle River, New Jersey, USA: Prentice Hall.

RPL. (n.d.). Regina Public Library: 2016-2021 Strategic Plan. Retrieved from https://www.reginalibrary.ca/sites/default/files/2017-08/RPL\%20Strategic\%20Plan\%2020162021.pdf.

Smith, A. (2010). Decolonization in unexpected places: Native evangelicalism and the rearticulation of mission. American Quarterly, 62(3), 569-590.

SPL. (n.d.). Saskatoon Public Library: Strategic Plan 2016 - 2021. Retrieved from https://saskatoonlibrary.ca/isl/uploads/2019/11/1068_StrategicPlan-final-web.pdf

Statistics Canada. (2016). Aboriginal Peoples highlight tables, 2016 census. [Catalogue number 98-402-X2016009]. Retrieved from https://www12.statcan.gc.ca/censusrecensement/2016/dp-pd/hlt-fst/abo-aut/Table.cfm?Lang=Eng\&T $=102 \& S=88 \& O=A$ 
Tembo, S. (2018). Reconciliation through long-range municipal plans: Lessons for Winnipeg, Faculty of Graduate Studies (Electronic Theses and Dissertations), URI: http://hdl.handle.net 11993/33470. Retrieved from https://mspace.lib.umanitoba.ca/bitstream/handle/1993/33470/Tembo_Sonikile.pdf?sequence $=1$.

TPL. (n.d.). Toronto Public Library, Strategic Plan 2020-2024. Retrieved from https://www.torontopubliclibrary.ca/content/about-the-library/strategic-plan/pdfs/strategicplan-2020-full-version-web-single-pages.pdf.

TPL (2017) Strategies for Indigenous Initiatives. Retrieved from https://www.torontopubliclibrary.ca/about-the-library/advisory-council/.

Truth and Reconciliation Commission of Canada (TRC). (2015). Honouring the Truth, Reconciling for the Future: Summary of the Final Report of the Truth and Reconciliation Commission of Canada. Retrieved from http://www.trc.ca/assets/pdf/Honouring_the_Truth_Reconciling_for_the_Future_July_23_20 15.pdf.

Vaismoradi, M., Turunen, H., and Bondas, T. (2013). Content analysis and thematic analysis: Implications for conducting a qualitative descriptive study. Nursing \& health sciences, 15(3), 398-405. https://doi.org/10.1111/nhs.12048.

Vaughan, C. (2018). The language of cataloguing: Deconstructing and decolonizing systems of organization in libraries. Dalhousie Journal of Interdisciplinary Management, 14, 1-15.

VPL. (2016). Vancouver Public Library: VPL 2020 Strategic Plan 2017-2020. Retrieved from https://www.vpl.ca/sites/vpl/public/VPL2020-Booklet_sml.pdf.

Wiebe, R. and Rathi, D. (2020). A Review of Library Associations Websites to Learn about Decolonizing Efforts. Proceeding of the $48^{\text {th }}$ Annual Conference of the Canadian Association for Information Science / l'Association canadienne des sciences de l'information (CAIS/ACSI), 1-6. https://doi.org/10.29173/cais1137.

WPL. (n.d.). Winnipeg Public Library: Strategic Plan 2015-2020. Retrieved from http://inspiringideas.wpl.winnipeg.ca/wp-content/uploads/WPL_StrategicPlan15-20E.pdf. 